\title{
Management of Dystocia Caused by Pygodidymus Monster in Crossbred Cattle
}

\author{
S.S. Dhindsa, Navgeet Singh*, Manna Baruti, Navjot Singh and Prahlad Singh \\ Department of Veterinary Gyanecology and Obstetrics, Guru Angaddev Veterinary and \\ Animal Sciences University, Ludhiana, Punjab - 141004, India \\ *Corresponding author
}

\section{A B S T R A C T}

\section{Keywords \\ Cattle, Conjoined twin, Fetotomy, Pygodidymus \\ Article Info \\ Accepted: \\ 26 October 2018 \\ Available Online: \\ 10 November 2018}

A rare case of conjoined twin monster-Pygodidymus in a crossbred cattle and its successful management by partial fetotomy is presented in the current report.

\section{Introduction}

Fetal monsters arise from adverse factors affecting the fetus in the early stages of its development. These factors are mostly of genetic origin but may also include physical, chemical or viral factors (Roberts, 1971).

A large number and type of monsters have been described in cattle that pose immense problems for the veterinarian as it is often impossible to palpate the whole structure per vaginum. The conjoined twins or double monsters arise from incomplete division of a fertilized ovum (Shukla et al., 2007). Most often conjoined twins with partial duplication of extremities and fusion in the anterior abdomen are encountered in bovine (Kumar et al., 2014). Pygodidymus is a rare monster when two calves are joined at the rump and facing in opposite directions. The delivery of such monsters is generally achieved by cesarean section (Saxena and Prakash, 1986) that further reduces the successful recovery of the dam owing to extra-long uterine incision to remove the monster that poses high risk of uterine adhesion formation. But in present report successful delivery of a rare Pygodidymus - conjoined twin monster was achieved by partial fetotomy in crossbred cattle.

\section{Case history and clinical observations}

A Holstein-Friesian crossbred cow at full term pregnancy was presented to the Teaching 
Veterinary Clinical Complex of Guru AngadDev Veterinary and Animal Sciences University, Ludhiana, India for the treatment of dystocia. The animal had calved twice earlier without any obstetrical complication and delivered normal calves. At presentation of the animal to our clinics, duration of dystocia was more than 12 hours, water bags had ruptured about 8 hours before and forced traction was applied for 4 hours at the field level by the local veterinarian in vain.

After complete anamnesis, vaginal and rectal examinations were performed to reveal the nature and cause of dystocia. Two forelimbs and head of the dead calf were presented in the birth canal and the case seemed resembling a hip lock condition. On critical vaginal examination another calf was found in posterior presentation that was attached to the right lateral rump area of the first calf and the case was diagnosed as a conjoined twin monster (pygodidymus).

\section{Treatments and Discussion}

In general, line of treatment for conjoined twin monsters is the cesarean section but the postcesarean complications viz. low survival of the dam, development of uterine adhesions, peritonitis and low subsequent fertility are the negative impacts of the surgery in bovine (Dhindsa et al., 2010). Realizing the production potential of the presented animal we quickly took the decision to perform fetotomy under epidural anaesthesia $(7 \mathrm{ml}, 2 \%$ Lignocaine hydrochloride).

A lubricated loaded fetotome was then inserted deep into the passage and fixed near rump area of the calf beyond the rib cage. A cut was given and first calf with head, forelimbs and thorax was extracted out carefully avoiding injury to the birth canal. The second calf was unable to deliver in posterior presentation due to the attached posterior part of first calf to it, thus, efforts were done to rotate the second calf within the uterus to bring it into anterior presentation following ample lubrication with 1 per cent solution of sodium carboxymethyl cellulose. To our surprise it was rotated well inside the uterus, by repelling the posterior end of the fetus and applying gentle traction to the other end, and we were able to catch hold of and snare up the forelimbs of the calf. An eye hook was applied to the right orbit of the calf, both hooves were cupped in hands to avoid injury to the birth passage and forced traction was applied carefully by pulling the snares tied to both forelimbs along with pressure on eye hook to deliver the calf.

The second calf was extracted out without any injury to birth canal and uterus (Fig. 1), and loose hanging fetal membranes were removed manually, whereas attached membranes were left in situ to shed off later on. On critical examination of fetal gross anatomy, the point of attachment between two male calves was at lateral rump area (sacrum of both calves) that was fused together, however other internal and external organs were in duplication. Following delivery, supportive therapy comprising of 5 litres of normal saline solution (IV), solution of calcium borogluconate together with magnesium and phosphorus $450 \mathrm{ml}$ (slow IV), antibiotics (Ceftiofur $2 \mathrm{mg} / \mathrm{kg}$ b. wt., IM) and nonsteroidal anti-inflammatory drugs (Flunixinmegludyne, $2 \mathrm{mg} / \mathrm{kg}$ b. wt., IM) was administered and other drugs viz. multivitamins, rumenotorics, ecbolics were prescribed as a routine treatment for one week.

The cow recovered well following the treatment. The owner was advised to supplement calcium and mineral mixture in the feed to maintain adequate production level, and to administer prostaglandin F2aanalogue (Cloprostenol sodium, $500 \mathrm{mcg}$, IM) 10 days post-delivery to boost uterine involution. 
Fig.1 Conjoined twin monster - pygodidymus delivered through fetotomy

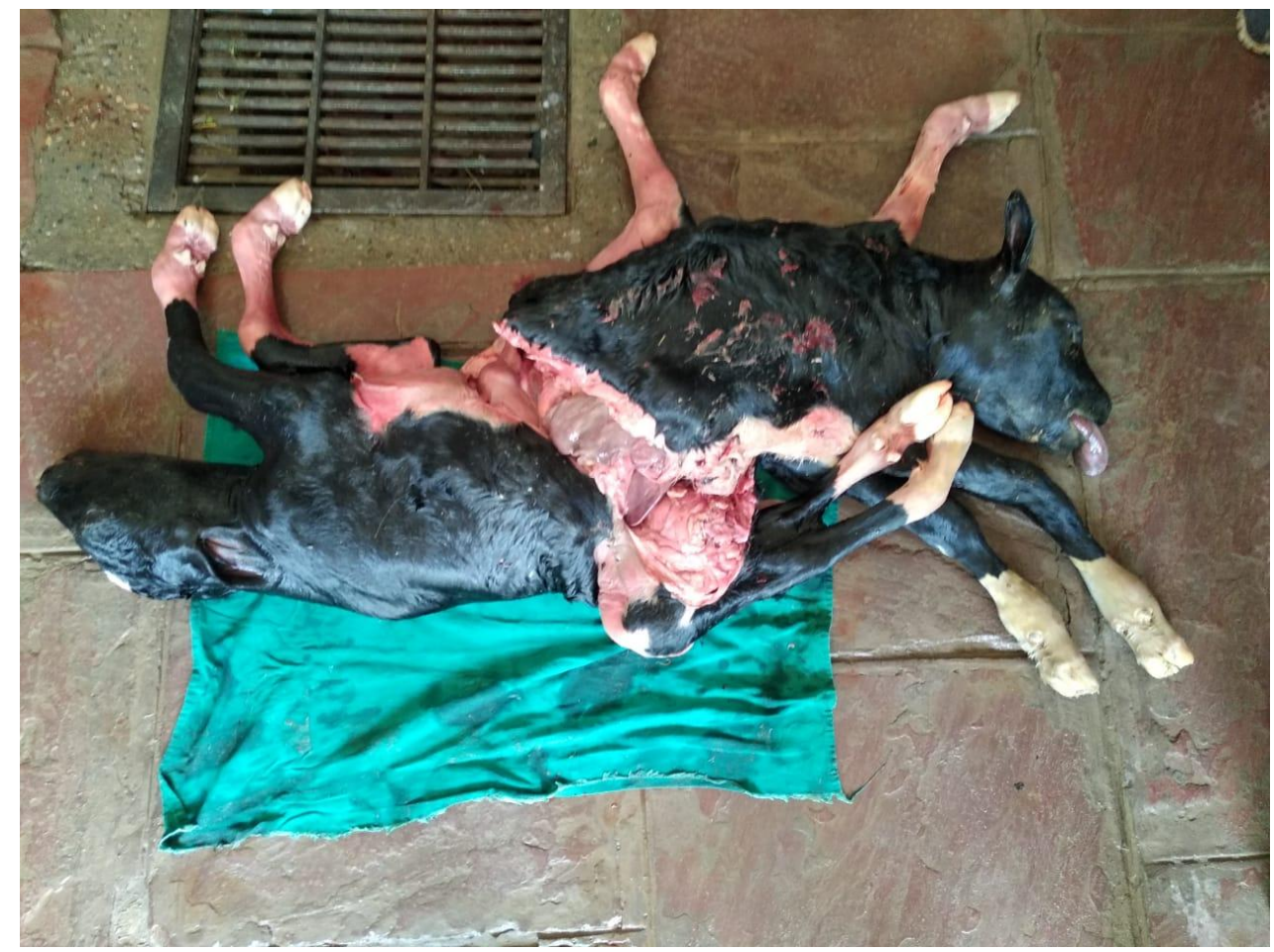

In cattle, fetus is considered as most common cause of dystocia (Bennett and Gregory, 2001) and developmental anomalies affecting the bovine embryos have been well recorded (Honnappagol et al., 2005). A low incidence $(0.5 \%)$ of monstrosities has been reported for cow (Purohit et al., 2012). Whitlock et al., (2008) have documented various developmental anomalies in bovine. The development of conjoined twins is one of the congenital abnormalities found in animals (Velhanker et al., 1968 and Chandrahasan et al., 2003). Conjoined twins are always identical twins of the same sex originate due to incomplete division of one fertilized egg (Kumar et al., 2014) at the primitive streak development state (Noden and Delahunta, 1985). These double monsters have considerable significance both from the obstetrical and embryological points of view. The cause of such conjoined twins remains mystery, however, many genetics and environmental factors, viral infection, poisoning of dam or nutritional deficiency viz. vitamin $\mathrm{A}$, folic acid etc. are considered to play role in development of such monsters (Jones and Hunt, 1983). The incidence of conjoined twins with almost complete duplication as observed in the present case is rare in bovine (Singh and Pandey, 2013). It is believed that such twins fail to separate into two fetuses after the $13^{\text {th }}$ day post fertilization (Srivastva et al., 2008). In conclusion, dystocia due to conjoined twin monsterpygodidymus may occur in cattle and can successfully be managed by fetotomy instead of cesarean section to improve prognosis of the condition.

\section{References}

Bennett, G.L., and Gregory, K.E. 2001. Genetic (co)variances for calving difficulty score in composite and parental populations of beef cattle: 1 . Calving difficulty score, birth weight, weaning weight and post-weaning gain. Journal of Animal Science.79:45-51. 
Chandrahasan, L., Krishna, K.K., and Selvaraju, M. 2003. Dystocia due to dicephalusmonostomus monster in a cross bred cow. Indian Journal of Animal Reproduction.24:175.

Dhindsa, S.S., Dhaliwal, G.S., Ghuman, S.P.S., and Sood, N.K. 2010. Alterations in uterine and peritoneal fluid cytology as well as uterine histopathology following caesarean operation with reference to suture material and intra-peritoneal lubricant in bovines. Indian Journal of Animal Sciences. 80(6): 523-527.

Honnappagol, S.S., Tandle, M.H., and Ramakrishna, V. 2005. Thoraco abdominopygophagus foetal monster in a non descript cow. Indian Veterinary Journal.82: 441.

Jones, T.C., and Hunt, R.D. 1983. Veterinary Pathology, $5^{\text {th }}$ edn., Lea and Febiger, Philidelphia., pp. 115.

Kumar, S., Pandey, A.K., Kushwaha, R.B., Sharma, U., and Dwivedi, D.K. 2014. Dystocia due to conjoined twin monster in a cow. Indian Journal of Animal Reproduction. 35(1): 54-56.

Noden, D., and Delahunta, A. 1985. The embryology of domestic animals. Williams and Wilkins, Baltimore, pp. 44-45.

Purohit, G.N., Kumar, P., Solanki, K., Shekher, C., and Yadav, S.P. 2012.
Perspectives of fetal dystocia in cattle and buffalo. Veterinary Science Development. 2: 231-242.

Roberts, S.J. 1971.Veterinary Obstetrics and Genital Diseases. $2^{\text {nd }}$ edn., Edwards Brothers, Inc. Ann Arbor, Michigan, US., pp. 281-285.

Saxena, O.P., and Prakash, P. 1986. Thoracopagus conjoined twins in cattle - a case report. Indian Veterinary Journal.63:470-472.

Shukla, S.P., Nema, S.P., Pandey, A.K., Jain, S., Patel, B.R., and Bondade, S. 2007. Dystocia due to bull dog calf in a she buffalo. Buffalo Bulletin.26:104-105.

Singh, G., and Pandey, A.K. 2013. Dystocia due to conjoined twin monsters in murrah buffaloes. Haryana Veterinarian.52: 139-140.

Srivastva, S., Kumar, A., Maurya, S.K., Singh, A., and Singh, V.K. 2008. A dicephlus monster in Murrah buffalo. Buffalo Bulletin. 27(3): 231-232.

Velhankar, D.P., Deshpande, B.R., and Hadi, M.A. 1968. Occurrence of Gastrothoracodidymusoctopes twin monsters in buffaloes. Indian Veterinary Journal.45:823-829.

Whitlock, B.K., Kaiser, L., and Maxwell, H.S. 2008. Heritable bovine fetal abnormalities. Theriogenology. 70: 535549.

\section{How to cite this article:}

Dhindsa, S.S., Navgeet Singh, Manna Baruti, Navjot Singh and Prahlad Singh. 2018. Management of Dystocia Caused by Pygodidymus Monster in Crossbred Cattle. Int.J.Curr.Microbiol.App.Sci. 7(11): 3384-3387. doi: https://doi.org/10.20546/ijcmas.2018.711.388 